\title{
La reversión de los bienes enajenados o cedidos por los Ayuntamientos por incumplimiento de las condiciones impuestas
}

\author{
Francisco Javier Ciria Pérez \\ Técnico de Grado Medio de Intervención del \\ Ayuntamiento de Tudela (Navarra)
}

Sumario: I. INTRODUCCIÓN. II. NORMATIVA APLICABLE A LOS BIENES DE LOS AYUNTAMIENTOS: 1) En general. 2) Específica de Navarra. III. NATURALEZA JURIDICA DE LOS CONTRATOS DE ENAJENACIÓN DE BIENES: 1) Antes de la nueva Ley de Contratos. 2) Tras la entrada en vigor de la Ley 13/1995, de Contratos. IV. LA INSTITUCIÓN DE LA REVERSION: 1) Antecedente legislativo. 2) Su regulación actual. 3) Una precisión terminologica. 4) Enajenaciones a las que es aplicable. 5) Causas concurrentes para que el bien pueda revertir. 6) Procedimiento administrativo a seguir. 7) Consecuencias del acuerdo de resolución o rescisión del contrato. V. CONCLUSIONES.

\section{INTRODUCCIÓN}

La Administración Pública, y formando parte de la misma los Ayuntamientos, tiene la obligación de prestar unos servicios públicos que satisfagan las necesidades de los ciudadanos y aumenten su calidad de vida. En relación con la prestación de estos servicios públicos, tienen gran importancia los bienes de los que es propietaria la Administración, bien sea como fuente de ingreso, bien como soporte material de los servicios públicos '. En otras ocasiones, la Administración pone a disposición de los ciudadanos o de empresas, de forma gratuita $u$ onerosa, algunos de sus bienes con la finalidad de fomentar una actividad que beneficie a los conciudadanos. Sin embargo, es habitual que en tales enajenaciones - con este término nos referiremos, en principio, tanto a las. ventas como a las cesiones gratuitas, a sabiendas de que incurrimos en una imprecisión- ${ }^{2}$ se impongan unas condiciones que, en caso de incumplimiento, hagan que el bien revierta al patrimonio municipal. Es de estas reversiones

\footnotetext{
1 Demetrio Loperena Rota, Defensa y recuperación de los bienes de las entidades locales, $\mathrm{n}^{\circ} 2$ de la colección Temas de Administración Local, editada por la Federación Navarra de Municipios y Concejos, Pamplona, 1988.

2 Remitimos al lector el epígrafe IV.4 en donde se contiene nuestra postura: «los conceptos de enajenación y cesión de bienes están debidamente diferenciados y contrapuestos, reservándose la última denominación para los que se hacen a título gratuito».
} 
y de la problemática que de ellas se deduce de lo que vamos a tratar en el presente trabajo.

\section{NORMATIVA APLICABLE A LOS BIENES DE LOS AYUNTAMIENTOS}

\section{En general}

El artículo 132.1 de la Constitución Española dice que «la Ley regulará el régimen jurídico de los bienes de dominio público y de los comunales, inspirándose en los principios de inalienabilidad, imprescriptibilidad e inembargabilidad, así como su desafectación».

Como recuerda RAzQuiN ${ }^{3}$ : «El artículo 132 citado recoge el principio de reserva de ley en materia de regulación del dominio público. En ese sentido, la sentencia del Tribunal Constitucional número 58/1982, de 27 de julio, aclara que el precepto constitucional se refiere tanto a la ley estatal como a la ley autonómica, debiendo remitirse por tanto la cuestión a la distribución de competencias recogida en los artículos 148 y 149 de la Constitución».

Con carácter general, la regulación sobre los bienes locales se encuentra en la Ley 7/1985, de 2 de abril, reguladora de las Bases del Régimen Local (LRBRL) (arts. 79 a 83), en el Texto Refundido aprobado por Real Decreto Legislativo 781/1986, de 18 de abril, (arts. 74 a 87) y, finalmente, en el Reglamento de Bienes de las Entidades Locales (RBEL), aprobado por Real Decreto 1372/1986, de 13 de junio. Es la Ley de Bases la que establece que el régimen de los bienes de las entidades locales se rige por la legislación básica del Estado dictada en desarrollo del artículo 132 de la Constitución, por la legislación de las Comunidades Autónomas y por las ordenanzas propias de cada entidad.

El artículo 1.2 del Reglamento de Bienes establece el orden de prelación de fuentes que regulan el régimen de bienes de las entidades locales.

\section{Específica de Navarra}

La Ley Paccionada de 16 de agosto de 1841, que continúa en vigor según la disposición final uno de la Ley Orgánica 13/1982, de 10 de agosto, de Reintegración y Amejoramiento del Régimen Foral de Navarra (LORARFNA), en cuan-

3 Martín M.: RazQuin LizarRaga: «Los bienes de las entidades locales de Navarra», en la obra colectiva La Administración Local de Navarra, dirigida por el propio Razquin y por Pedro M." Larumbe Biurrun, Editorial Aranzadi, 1987. 
to no se oponga a lo establecido en la propia Ley Orgánica, en sus artículos 6 y 10 , atribuye a la Diputación la potestad de regular el régimen de los bienes de los pueblos. Más adelante, en el Decreto-Ley de 4 de noviembre de 1925, se especificó tal competencia en la Base 3. LOPERENA nos dice que «éste es el título competencial actualmente vigente ya que el art. 46.1.a) del Amejoramiento dice que Navarra conserva las facultades y competencias que ostentaba con anterioridad» ${ }^{4}$.

La Ley Foral 6/1990, de 2 de julio, de la Administración Local de Navarra ${ }^{5}$ (LFALN), establece el sistema de fuentes para los bienes de las entidades locales de Navarra, que se rigen por: esa misma Ley y sus disposiciones reglamentarias; las restantes normas del Derecho Administrativo Foral de Navarra; las ordenanzas de la respectiva entidad; $y$, en su defecto,.por las normas del Derecho Privado Foral, sin perjuicio de lo dispuesto en el apartado tercero del artículo 40 de la LORARFNA ${ }^{6}$.

Posteriormente, se aprobó, por Decreto Foral 280/1990, de 18 de octubre, el Reglamento de Bienes de las Entidades Locales de Navarra, en adelante RBELN ${ }^{7}$.

4 Demetrio LoPerena Rota, obra citada, pág. 16.

5 Demetrio LOPERENA ROTA, en la obra que venimos mencionando, anticipaba: «En el momento en que Navarra apruebe su nueva Ley Municipal podrá disponer de un régimen propio también para los bienes de dominio público y los patrimoniales, respetando la legislación básica del Estado».

6 En la Memoria elaborada por el Departamento de Administración Local del Gobierno de Navarra para el proyecto de Ley Foral de la Administración Municipal de Navarra - después se aprobó con el adjetivo Local- se contiene una explicación de por qué se ha desarrollado de una forma tan amplia la cuestión de los bienes de las entidades locales de Navarra en esta Ley Foral:

«El Proyecto de Ley Foral trata ampliamente la materia de bienes, por entenderse que la regulación que de los mismos se hace puede resultar nueva en el régimen local de Navarra.

Efectivamente, el Reglamento para la Administración Municipal de Navarra dedicaba todo el Título IV a los montes y comunes de los pueblos. Este Título que además contaba con cinco Apéndices trataba fundamentalmente de la administración de los montes y terrenos comunales y aguas patrimoniales, etc. Además, el Capítulo I del Título V del Reglamento para la Administración Municipal de Navarra, comenzaba definiendo el patrimonio comunal de las entidades locales, que estaba constituido por todos los bienes, acciones y derechos que pertenecieran a los pueblos.

Es decir, el Reglamento para la Administración Municipal de Navarra prácticamente no venía a considerar más que la existencia de bienes comunales.

Por otra parte, la prelación de normas que establece en esta materia la Ley de Bases de Régimen Local, y la poca extensión dedicada a la materia de su articulado, hace que sea preciso un amplio desarrollo por parte de la legislación autonómica (...).

Pero es el régimen de fuentes aplicable a los bienes locales y la, hasta ahora, falta de clarificación conceptual y de utilización práctica que ha existido en Navarra lo que conduce a que el proyecto sea prolijo en esta materia. En él ya no se define el patrimonio comunal sino el patrimonio de las entidades locales y se establece la dicotomía tradicional en calificar los bienes como de dominio público o patrimoniales. El proyecto ha incorporado los contenidos en la Ley Foral de Comunales — de 28 de mayo de 1986-. adaptando únicamente su sistema al conjunto del Título y manteniendo en su integridad aquel texto.»

7 En Navarra, respecto al tema objeto de este trabajo, ha habido la siguiente evolución reglamentaria: 


\title{
III. NATURALEZA JURÍDICA DE LOS CONTRATOS DE ENAJENACIÓN DE BIENES
}

No es ésta una cuestion fundamental en relación con el nudo gordiano de este trabajo, pero no queremos pasarla por alto puesto que normalmente se plantea cuando un ayuntamiento acuerda la reversión de un determinado bien: mientras que la Administración defiende que se trata de un contrato administrativo, los particulares suelen querer llevarlo al ámbito civil.

Para un correcto análisis de la naturaleza jurídica, creemos que tras la entrada en vigor de la Ley 13/1995, de 18 de mayo, de Contratos de las Administraciones Públicas (LCAP), hay que reflexionar al respecto teniendo precisamente en cuenta lo que para esta Ley son contratos administrativos y civiles. Así pues, abordaremos esta clasificación con anterioridad y con posterioridad a la entrada en vigor de la nueva Ley de Contratos.

\section{Antes de la nueva Ley de Contratos}

Hasta la entrada en vigor de la LCAP la jurisprudencia del Tribunal Supremo (TS) había establecido unos parámetros que identificaban el tipo de contrato (administrativo o civil).

Nos encontramos con una Sentencia (S.) ya vieja, la de 20 de abril de 1936 (R. 1010), pero que aborda esta cuestión con los siguientes términos:

\begin{abstract}
«Que a falta de notas diferenciales absolutas entre el contrato civil y el contrato administrativo, cuando la materia es tan discutible y multivoco (sic) como la correspondiente a la compra venta en que intervienen particulares y Estado, conviene polarizar su naturaleza en dirección al superior interés colectivo del servicio público; y por lo tanto, si la Administración es accidente en tal ejercicio de tal actividad de función o colocación de esta misma actividad, parece natural que el vendedor particular se repute entregado a la jurisdicción competente para conocer de las contestaciones que surjan dentro de la órbita jurídico-administrativa; y es más categórico el vínculo de sumisión específica a las reglas del Derecho público, cuando en el respectivo contrato se establecen cláusulas exorbitantes o derogatorias del Derecho común que asumen la consideración de una competencia administrativa retenida, tales como las consignadas en las estipulaciones con referencia a un pliego de cláusulas y condiciones generales, elaborado por la Administración para las necesidades y atenciones de los servicios públicos, las cuales, por no hallar equivalentes en el Derecho civil, donde juegan los elementos personales en plano de igualdad, sólo perte-
\end{abstract}

- Reglamento de Bienes de 1955: desde el 14 de julio de 1955 hasta el 6 de julio de 1986.

- Reglamento de Bienes de 1986: desde el 7 de julio de 1986 hasta el 30 de noviembre de 1990.

- Reglamento de Bienes de 1990, propio de Navarra: desde el 1 de diciembre de 1990. 
LA REVERSIÓN DE LOS BIENES ENAJENADOS O CEDIDOS ...

necen al dominio de los poderes estatales que las imponen a virtud de imperio y otorgan por consiguiente al acto contractual un carácter de adhesión, que los sumerge de lleno en la jurisdicción contencioso-administrativa.»

Más recientemente, el Tribunal Supremo (SS 26 de junio de 1965, R. 3621, y 25 de septiembre de 1970, R. 3742), reconoció:

«Que si bien es cierto que no existe una línea divisoria para deslindar los campos de lo estrictamente civil y de lo fundamentalmente administrativo, la doctrina y la jurisprudencia han establecido normas para determinar la naturaleza jurídica del contrato administrativo atendiendo principalmente a los elementos subjetivos; el carácter y posición con que actuaron las partes; el objeto, alcance y finalidad de los mismos y a si la relación contractual tiende de modo inmediato y directo a la ejecución de una obra o prestación de un servicio, por lo cual se hace preciso estudiar tales elementos para poder deducir de ellos, cuál sea la naturaleza jurídica de tales contratos ...».

En consecuencia, pues, no hay más remedio que examinar uno a uno los citados elementos para poder calificar el contrato de civil o de administrativo. Veamos qué pronunciamientos ha hecho el Alto Tribunal respecto a cada uno de esos elementos:

\section{a) Elementos subjetivos}

Es obvio que no basta con que una de las partes contratantes sea la Administración para calificar el contrato de administrativo; sino que habrá que estar a la capacidad que aquélla demuestra (civil o administrativa). Al respecto, podemos mencionar la STS de 25 de noviembre de 1991 (R. 9182):

«No basta, pues, para la competencia de esta Jurisdicción con que exista un acto de la Administración, sino que es imprescindible que se trate de un acto sujeto al Derecho Administrativo, lo que no sucede cuando la materia objeto del recurso está aforada a la jurisdicción civil —STS 26 de septiembre de 1986 (RJ 198615996)—, ...».

«... la STS 22 de enero de 1975 (RJ 197518) distingue como civil un contrato de la Administración Pública cuando ésta actúa con capacidad privada y su objeto sea un derecho civil, y como administrativo cuando el objeto sea una obra o servicio público, cualquiera que sea la capacidad del sujeto. En el mismo sentido se pronuncí́ la STS 25 de septiembre de 1970 (RJ 197013742), recogiendo la doctrina contenida en la de 26 de junio de 1965 (RJ 196513621), ...».

También se puede citar la S. de 5 de octubre de 1983 (R. 5228), Sala de lo Civil:

«... tanto la doctrina moderna como la jurisprudencia -SS de 3 de enero de 1962 (R. 37), 15 de octubre de 1963 (R. 4121 ), 26 de febrero de 1966 (R. 1992) y la de 11 de mayo de 1982 (R. 2566) - han matizado la distinción entre el contrato civil y el administrativo, en el sentido de cargar el acento diferencial en el fin perseguido 
por el convenio, es decir, que sería administrativo cuando lo fuese referido a obras y servicios públicos, no cuando meramente interviene la Administración, ...».

\section{b) Carácter y posición de las partes}

Ya hemos visto como para la Sentencia de 20 de abril de 1936 es categórico para calificar el contrato de administrativo el hecho de que en el contrato se establezcan cláusulas exorbitantes en favor de la Administración, las cuales no tienen equivalentes en el Derecho civil, donde las partes están en una posición de igualdad.

Es decir, como dice la ya citada Sentencia de 25 de septiembre de 1970, estaremos ante un contrato administrativo cuando la Administración lo concierta,

«... no en una posición de igualdad ..., sino con imperio y como tal persona pública, prueba de ello es que redacta un pliego de condiciones en modo de "cliché legal" $\mathrm{y}$ al cual habrian de sujetarse, si querían adquirir el solar de autos, constituyendo tal realidad una figura similar al contrato de adhesión, pliego de condiciones que no suele haber en el campo privado, posición de superioridad del Ayuntamiento ... que también se deduce desde el contenido de la aludida figura contractual, al establecer una "cláusula exorbitante", ..., cláusula reversional ...».

Parece pues que basta la existencia en el contrato de cláusulas exorbitantes -entre las que se encuentra la reversional, que es objeto de este trabajo- para que haya que calificarlo de administrativo: SS. de 9 de octubre de 1957 (R. 2780), 25 de septiembre de 1970 (R. 3742), 13 de noviembre de 1972 (R. 4730 ), 16 de noviembre de 1972 (R. 4748), 16 de noviembre de 1973 (R. 4107) y 29 de diciembre de 1986 (R. 1676/1987), entre otras.

\section{c) Objeto, alcance y finalidad de los mismos; atención de una obra o prestación de un servicio.}

No hay que olvidar, como lo hace el Tribunal Supremo en su Sentencia de 2 de diciembre de 1969 (R. 5596):

«... el carácter formalista de la contratación administrativa, en contraste con los principios espiritualistas que dominan la contratación civil; y esto por el predominio del interés público que informa el servicio que la Administración contrata».

Y hemos también de recordar que, junto con los contratos administrativos nominados o tipificados, se pueden enunciar otros que podemos calificar de "contratos administrativos especiales», que son aquéllos en los que concurre alguna de estas dos circunstancias: directa vinculación al desenvolvimiento regu- 
LA REVERSIÓN DE LOS BIENES ENAJENADOS O CEDIDOS ..

lar de un servicio público, o que revista características intrínsecas que hagan precisa una especial tutela del interés público para el desarrollo del contrato, bien entendido que la existencia de una sola de estas dos notas es suficiente para que un contrato no sea privado (S. 24 de diciembre de 1985, R. 6405).

Partiendo, pues, de que la actuación administrativa tiene que buscar la satisfacción del interés público, estamos ya entreviendo cuál tiene que ser el objeto o la finalidad de los contratos para que su naturaleza jurídica sea administrativa. Más amplia parece ser la interpretación que aparece en la Sentencia de 15 de febrero de 1971 (R. 785):

«Que en orden a la naturaleza jurídica del acto es preciso señalar que se trata de un contrato de carácter administrativo, y para afirmarlo así nos hemos de basar en el criterio diferenciador de la finalidad que persigue, recogido en el art. $3 .^{\circ}$ de la Ley de la Jurisdicción cuyo texto atribuye a ésta el conocimiento de las cuestiones referentes a los contratos celebrados por la Administración pública, cuando tuvieren por finalidad obras y servicios de toda especie, expresión que ha de interpretarse en un sentido amplio similar al interés público o general, ...».

También la S. del 2 de marzo de 1973 (R. 971) hace referencia a la interpretación amplia que hay que dar a la expresión «obras y servicios».

El Tribunal Supremo se ha valido en otras ocasiones del precio recibido por la Administración para concluir que el contrato era administrativo (S. 25 de septiembre de 1970, R. 3742):

«... ni desde el punto de vista del objeto del contrato de autos, ni de su finalidad, el contrato referido tampoco puede subsumirse en el campo del Derecho privado, habida cuenta que por lo que respecta al objeto, es evidente que el mismo, para el Ayuntamiento recurrido, no fue el precio que en él se pact $6-10.000$ pesetas-, poco más de 6 pesetas el metro cuadrado, cantidad irrisoria ..., criterio extensible en cuanto al aspecto teleológico del recurso, pues la finalidad de dicho contrato no fue obtener esas aludidas 10.000 pesetas por parte de la Corporación, sino que, con antelación a tal finalidad estrictamente crematística, el Ayuntamiento ... perseguía ... [una] finalidad pública cuyo cumplimiento determino se estipularan en el contrato de litis la "cláusula exorbitante"...".

En igual sentido encontramos también las SS. del 13 de noviembre de 1972 (R. 4730) y 25 de noviembre de 1996 (R. 8229).

También merecerán la calificación de contratos administrativos los celebrados entre una Corporación Local y un particular que tengan por objeto la enajenación de bienes comunales, al ser dichos bienes equiparables a los de dominio público en lo que afecta a su régimen jurídico (S. 9 de febrero de 1985, R. 1007). 
A modo de resumen, podemos sacar a colación la S. de 29 de diciembre de 1986 (R. 1676/1987):

«... su naturaleza administrativa resulta evidente de acuerdo entre otras muchas, con las Sentencias de este propio Tribunal de 12 de noviembre de 1980 (R. 4489) y 12 de abril de 1984 (R. 1995), que reconocen esta naturaleza a todos los contratos celebrados por la Administración cuya finalidad sea la satisfacción directa o indirecta de una necesidad pública como declaramos también para casos de reversión de terrenos, en Sentencias de 21 de junio de 1976 (R. 4172) y 27 de septiembre de 1983 (R. 5771) entre otras; ...».

Así, la jurisprudencia ha calificado de contratos administrativos las ventas o cesiones gratuitas destinadas o supeditadas a los siguientes fines:

- Urbanizar la zona donde el solar enajenado estaba enclavado: SS. 25 de septiembre de 1970 (R. 3742), 13 de noviembre de 1972 (R. 4730), 16 de noviembre de 1972 (R. 4748), 21 de noviembre de 1972 (R. 5049) y 11 de noviembre de 1985 (R. 359/1986).

- Que otra Administración preste un servicio público: SS. 16 de noviembre de 1973 (R. 4107) y 8 de mayo de 1962 (R. 2209).

- Fomento a la industria: SS. 28 de marzo de 1978 (R. 1388), 11 de diciembre de 1978 (R. 134/1979), 23 de octubre de 1985 (R. 6292), 25 de noviembre de 1996 (R. 8229) y 26 de mayo de 1997 (R. 3984).

- Construcción de viviendas: SS. 9 de febrero de 1985 (R. 1007), 4 de noviembre de 1986 (R. 7747), 5 de enero de 1988 (R. 185), 15 de mayo de 1990 (R. 4075), 28 de febrero de 1995 (R. 1079), 24 de enero de 1996 (R. 34) y 11 de junio de 1996 (R. 6123).

- Construcciones para educación (fines universitarios, centro escolar o guardería infantil): SS. 15 de febrero de 1971 (R. 785), 29 de diciembre de 1986 (R. 1676/.1987), 28 de diciembre de 1987 (R. 9848), 10 de diciembre de 1988 (R. 9772) y 18 de junio de 1996 (R. 5232).

- Construcción de casa sindical (extinguida Organización Sindical): SS. 3 de febrero de 1986 (R. 894), 18 de junio de 1990 (R. 4766) y 27 de febrero de 1993.(R. 1303).

- Construcción de dependencias para instituciones del régimen político franquista: SS. 23 de junio de 1987 (R. 6521) y 31 de octubre de 1988 (R. 8338). 
LA REVERSION DE LOS BIENES ENAJENADOS O CEDIDOS ..

- Construcción de un granero-almacén: S. 23 de noviembre de 1992 (R. 9210).

- Distribución de fincas entre agricultores dentro de un procedimiento de concentración parcelaria: S. 24 de diciembre de 1985 (R. 6405).

Por contra, en la S. de 11 de junio de 1970 (R. 3373) se califica de civil un contrato en el que se vendía un solar cuyo único destino era la construcción de un hotel de primera categoría.

\section{Tras la entrada en vigor de la Ley $13 / 1995$, de Contratos ${ }^{8}$}

Parece, a primera vista, que la Ley $13 / 1995$ ha unificado la posible naturaleza dual de los contratos de enajenación de bienes a que hemos hecho referencia en el apartado anterior. El artículo 5, en sus números 2 y 3 , dispone:

«2. Son contratos administrativos:

a) Aquellos cuyo objeto directo, conjunta o separadamente, sea la ejecución de obras, la gestión de servicios públicos y la realización de suministros, los de consultoría y asistencia o de servicios y los que se celebren excepcionalmente con perso-

8 No queremos ni podemos dejar de indicar la controversia que hay en Navarra sobre la aplicación de la Ley 13/1995. El motivo está en que el artículo 49.1.d) de la LORARFNA establece que: «En virtud de su régimen foral, corresponde a Navarra la competencia exclusiva sobre las siguientes materias: d) Contratos y concesiones administrativas, respetando los principios esenciales de la legislación básica del Estado en la materias. En el Boletín Oficial del Parlamento de Navarra (BOPN) del 16 de febrero de 1996 aparece una pregunta al respecto, la cual tiene cumplida respuesta por la Diputación Foral en el Boletín de fecha 25 de marzo de 1996:

«Nos imaginamos que el Parlamentario de UPN se está refiriendo a la expresión "principios esenciales de la legislación básica del Estado" a que, en materia de contratación administrativa, hace referencia el artículo 49.1.d) del Amejoramiento. La cuestión es si cabe interpretar que el citado artículo atribuye a Navarra mayores competencias que las que tienen el resto de las Comunidades.

El texto que en un futuro remita el Gobierno al Parlamento será un reflejo de la postura adoptada al respecto, y sólo el Tribunal Constitucional podrá determinar el sentido que cabe dar a la expresión "principios esenciales de la legislación básica", en caso de que entre a examinar la constitucionalidad de los cambios normativos que se introduzcan».

En el BOPN de 26 de febrero de 1996 se publicó un informe de la Cámara de Comptos sobre la regulación de la contratación administrativa, en el que se decía:

"La Comunidad Foral de Navarra, en virtud de lo dispuesto en el artículo 49.1.d) de la LORAFNA tiene competencia exclusiva en materia de "contratos y concesiones administrativas", respetando los principios esenciales de la legislación básica del Estado.

Así pues, Navarra ostenta en esta materia una competencia más amplia que las restantes CC.AA., ya que éstas resultan vinculadas totalmente por las bases que dicte el Estado, en tanto que aquélla lo está sólo por sus principios esenciales.

(...) el Parlamento de Navarra — al igual que quienes ostentan la iniciativa legislativa — ha de pronunciarse, con carácter previo, respecto a una capital cuestión de política legislativa: la forma y alcance con que va a ejercer la compentencia de carácter "histórico" de que Navarra es beneficiaria en materia de contra- 
nas físicas para la realización de trabajos específicos y concretos no habituales.

b) Los de objeto distinto a los anteriormente expresados pero que tengan naturaleza administrativa especial por resultar vinculados al giro o tráfico específico de la Administración contratante, por satisfacer de forma directa o inmediata una finalidad pública de la específica competencia de aquélla o por declararlo así una Ley.

3. Los restantes contratos celebrados por la Administración tendrán la consideración de contratos privados y, en particular, los contratos de compraventa, donación, permuta, arrendamiento y demás negocios jurídicos análogos sobre bienes inmuebles, propiedades incorporales y valores negociables».

Sin embargo, nosotros creemos que una enajenación de un bien propiedad de un ayuntamiento puede seguir teniendo una naturaleza administrativa, especial eso sí, por cuanto puede encajar perfectamente en el art. 5.2.b) reproducido al satisfacerse con dicha enajenación de forma directa o inmediata una finalidad pública de la específica competencia de la Administración.

Pero, si bien es importante determinar la naturaleza, administrativa o civil, de los contratos de enajenación de bienes, ya que será la jurisdicción contencioso-administrativa o la civil la competente para resolver las controversias que surjan, estimamos que, en relación con el objeto de este trabajo - la reversión de los bienes enajenados-, se relativiza bastante, si bien no hemos de olvidar que de tratarse de un contrato civil, el ejercicio de la potestad de recuperación posesoria de oficio solamente se podrá llevar a cabo en el plazo de un año contado desde el día siguiente a la fecha en que se haya producido la usurpación, debiéndose acudir a los tribunales ordinarios una vez transcurrido dicho plazo.

\section{LA INSTITUCIÓN DE LA REVERSIÓN}

\section{Antecedente legislativo}

El antecedente legislativo común para Navarra y para el resto del Estado sería el artículo 97 del Reglamento de Bienes de las Entidades Locales, aprobado por Decreto de 27 de mayo de 1955, que quedó expresamente derogado por la disposición adicional segunda del Reglamento de Bienes de las Entidades Locales, aprobado por Real Decreto 1372/1986, de 13 de junio. Estos Reglamentos es-

ción pública.

Y si tal competencia pretende ejercerse con plenitud es de rigor el análisis y estudio previo de aquellos principios esenciales estatuidos por la LCAP que la Comunidad Foral ha de respetar, así como otros mandatos normativos convergentes con la contratación y contenidos en dicha ley que el Estado ha dictado en virtud de otros títulos competenciales específicos y que, igualmente, limitan la competencia foral». Finalmente, indicar que la controversia también se planteó en el Ayuntamiento de Pamplona, recogiéndose en el Diario de Navarra el día 5 de mayo de 1996, en un artículo titulado «Ley Foral versus Ley Estatal». 
tatales tenían todo el valor doctrinal necesario para integrar el ordenamiento jurídico peculiar de Navarra hasta la entrada en vigor del Reglamento de Bienes de las Entidades Locales de Navarra, que se produjo el 1 de diciembre 1990, pues, al respecto, no tenía normas propias ${ }^{9}$.

Conviene reproducir el artículo 97, dado que a él se va a hacer referencia en muchas de las sentencias que posteriormente vamos a reproducir:

«1. Todas las cesiones de bienes patrimoniales quedarán sujetas a estas condiciones:

a) que los fines para los cuales se hubieren otorgado se cumplan en el plazo máximo de cinco años; $y$

b) que su destino se mantenga durante los treinta siguientes.

2. Transcurridos uno u otro plazo sin que se hubieren cumplido las citadas condiciones, los bienes revertirán automáticamente de pleno derecho al patrimonio de la Entidad cedente con sus pertenencias y accesiones».

\section{Su regulación actual}

El artículo 111 del RBEL dice:

«1. Si los bienes cedidos no fueren destinados al uso dentro del plazo señalado en el acuerdo de cesión o dejaren de serlo posteriormente se considerará resuelta la cesión y revertirán aquéllos a la Corporación local, la cual tendrá derecho a percibir de la Entidad beneficiaria, previa tasación pericial, el valor de los detrimentos experimentados por los bienes cedidos.

2. Si en el acuerdo de cesión no se estipula otra cosa, se entenderá que los fines para los cuales se hubieran otorgado deberán cumplirse en el plazo máximo de cinco años, debiendo mantenerse su destino durante los treinta años siguientes.

3. Los bienes cedidos revertirán, en su caso, al patrimonio de la Entidad cedente con todas sus pertenencias y accesiones».

En parecidos términos está el artículo 135 del RBELN:

«1. El acuerdo de cesión podrá contener cuantos condicionamientos, limitaciones o garantías se estimen oportunos.

Si en el acuerdo no se estipula otra cosa, las cesiones de propiedad de bienes patrimoniales quedarán sujetas a las siguientes condiciones:

9 Remitimos a la nota número 7. 
a) Que los fines para los que se hubiesen otorgado se cumplan en el plazo máximo de cinco años.

b) Que su destino se mantenga durante los treinta años siguientes.

2. Incumplidos los condicionamientos, limitaciones o garantías impuestas, la propiedad de los bienes revertirá de pleno derecho al patrimonio de la entidad local con sus pertenencias y accesiones».

No se puede confundir la posibilidad que tienen las Corp raciones de recobrar sus bienes patrimoniales por sí en el plazo de un año a c sntar desde el hecho de la usurpación con la reversión aquí analizada. Como dice la $\mathrm{S}$. de 25 de septiembre de 1970 (R. 3742):

«... aquélla previene de la Ley, ésta del contrato, allí se trata de una usurpación de bienes patrimoniales de una Corporación, aquí de una posesión que se detenta en virtud de título legítimo, ejercitándose esta reversión en virtud de haberse así pactado en un contrato de naturaleza pública...».

\section{Una precisión terminológica}

Con frecuencia nos encontramos con la utilización indistinta de los términos «reversión» y «rescisión»; pero, hemos de preguntarnos si son lo mismo, si se refieren a lo mismo, si su significado es el mismo. Como, a nuestro juicio, suele ser la mejor manera de aclarar unos conceptos jurídicos, nos acercaremos a la jurisprudencia del Tribunal Supremo, que, en relación con el tema que estamos tratando, también se ha visto obligado a realizar una precisión semejante a la que ahora nos ocupa, si bien no lo ha hecho con unanimidad de doctrina.

El 25 de septiembre de 1970 (R. 3742), el TS acepta el tercer considerando de la sentencia apelada, y en éste, con respecto a la cláusula reversional, se decía:

«... cláusula que en nada se parece a la facultad similar del Derecho privado, ni incluso a la cláusula resolutoria del art. $1124 \mathrm{del} \mathrm{C.} \mathrm{Civ.,} \mathrm{...,} \mathrm{la} \mathrm{cual} \mathrm{rompe} \mathrm{con} \mathrm{el} \mathrm{prin-}$ cipio de igualdad y limitar de las partes exigible y existente en los contratos de Derecho privado, ...».

Para la Sentencia de 11 de diciembre de 1978 (R. 134/1979), procede hablar de reversión cuando la cesión ha sido gratuita y de resolución o rescisión si la enajenación fue una venta onerosa:

«... la Administración vendedora puede, como también aquí sucedió, introducir una cláusula reversional que tiene el valor de estipulación contractual válida, pero que no cabe confundir con la imperativa limitación legal del ... Regl. de Bienes y ha de ser tratada en función de la interpretación del contrato, no de la Ley. (...). Y como último argumento cabe también considerar que el término "reversión" no contempla sino un as- 
LA REVERSIÓN DE LOS BIENES ENAJENADOS O CEDIDOS ..

pecto unilateral (la reintegración de la cosa a su anterior estado o situación) que se corresponde con el carácter unilateral de la cesión gratuita o donación, aunque concurra una carga modal, en tanto que tratándose de una enajenación o títuio oneroso el término adecuado sería el de rescisión o resolución de efecto bilateral y recíproco; ...».

Las SS. de 16 y 21 de noviembre de 1972 (R. 4748 y 5049), ante enajenaciones onerosas, en el considerando quinto de las sentencias apeladas, que se aceptan, dicen:

«Que, en cuanto al referido art. $6^{\circ}$ del pliego de condiciones, establece para los adquirentes la obligación de edificar en cierto plazo con la consecuencia, para el caso de incumplimiento, de pérdida de la propiedad, según se dice, que revertirá al Ayuntamiento, dado que la clase de contrato [previamente fue calificado de administrativo] y la índole de las obligaciones en ellos establecidas, son las que corresponderían por razón de la denominación, o términos empleados por las partes, según la Sala Primera del TS ha establecido en sentencias como la de 27 de junio de 1946 (R. 842 bis), nos encontramos en este caso con una condición que es resolutoria, por cuanto en contraposición a las suspensivas, puede dar lugar a la ineficacia del contrato por resolución del mismo; ...».

Finalmente, encontramos la S. de 4 de noviembre de 1986 (R. 7747), referida a una compraventa:

«... la Comisión Municipal Permanente, que con sus decisiones no puede vincular al órgano plenario competente para resolver el contrato y acordar la reversión de la parcela, ...».

De estas tres últimas sentencias reproducidas, creemos que se desprende que no hay exclusión de ambos términos, sino que se complementan, sin que tenga importancia que estemos ante una enajenación onerosa o gratuita. La reversión es la retrocesión al patrimonio de la Administración de los bienes objeto de enajenación (bien mediante venta, bien por cesión gratuita). En consecuencia pues, a nuestro juicio, la reversión debe seguir a la resolución del contrato, siendo una consecuenciạ de ésta.

\section{Enajenaciones a las que es aplicable}

Cabe preguntarse a continuación a qué enajenaciones es aplicable la institución que nos ocupa: si solamente a las gratuitas o también a las onerosas. No ha sido una cuestión pacífica en la doctrina de nuestro Tribunal Supremo, como a continuación tendremos ocasión de comprobar, si bien previamente acudiremos a ver lo que la doctrina científica ha dicho al respecto. 
Tomás CoBo Olvera ${ }^{10}$, tras reproducir el artículo 111 del RBEL, opina que:

«La reversión se produce en relación a las enajenaciones gratuitas, toda vez, que en principio, son las únicas a las que se les puede imponer condiciones».

Más adelante, añade:

«A hora bien, puede ocurrir, como hemos visto en páginas ante iores, que se enajenen bienes de forma onerosa, pero con ciertos condicionamientos.

En estos supuestos si no se cumplen las condiciones impuestas, o para evitar que se incumplan, entendemos que la figura más acorde para rescindir el contrato, sería la fijación en el pliego de condiciones, necesario para la enajenación, de una cláusula resolutoria para el supuesto de incumplimiento de las condiciones impuestas».

También Ángel Ballesteros Fernández " es de la misma opinión cuando se responde a la pregunta ¿afecta la reversión sólo a las cesiones gratuitas, o también a las enajenaciones onerosas en las que se haya establecido el fin concreto de la transmisión?:

«No hay duda ninguna si se ha pactado en el contrato de venta, y como condición resolutoria expresa, la afectación del bien a un fin determinado, que el incumplimiento del fin provoca la resolución de la venta; pudiendo afectar esta resolución a terceros, si la condición resolutoria se hubiere inscrito expresamente en el Registro de la Propiedad (arts. 9.2 y $37.1 .^{\circ} \mathrm{LH}$ ).

Tampoco ofrece duda la reversión, en el caso de cesión gratuita, aunque nada se hubiere pactado al respecto, porque, entonces, entra en juego la regla imperativa del artículo $111 \mathrm{RB}$ que estamos analizando».

Parece que ambos autores coinciden en:

1. Si ha sido una enajenación gratuita, entra en juego la reversión por imperativo del art. 111 del RBEL (en Navarra sería el art. 135 del RBELN).

2. ${ }^{\circ}$ Si la enajenación ha sido onerosa, para que proceda la reversión sería necesario que previamente, en el pliego de condiciones, se hubiese recogido expresamente una cláusula resolutoria.

Evidentemente, hemos de estar de acuerdo con estos autores, pues no hay duda de que si la enajenación fue gratuita y ha habido incumplimiento, entraría

10 Tomás Сово OlverA, «Régimen jurídico de la enajenación de los bienes de las entidades locales», Revista Actualidad Administrativa, n.11, 15-21 de marzo de 1993.

11 Ángel Ballesteros Fernández, Los bienes de las entidades locales, n. 17 de la colección Manual del Alcalde, publicada por el Banco de Crédito Local de España, 1." edición, julio 1987. 
LA REVERSIÓN DE LOS BIENES ENAJENADOS O CEDIDOS ..

en juego la reversión regulada en los Reglamentos de Bienes que venimos citando, aunque no estuviese estipulada en el pliego de condiciones [se pueden consultar al respecto las SS. de 27 de febrero de 1993 (R. 1303) y 18 de junio de 1990 (R. 4766), ambas de la Sala de lo Civil], y si la enajenación fue onerosa y se ha recogido en el pliego de condiciones la reversión $\longrightarrow$ resolución o rescisión, que para lo que ahora comentamos es lo mismo- extendería sus efectos al ser el contrato lex inter partes, con fuerza vinculante para las partes contratantes.

Ahora bien, tendremos que despejar la duda que surge de inmediato: ¿hay que aplicar la cláusula reversional si la enajenación fue onerosa y no se puso en el pliego de condiciones dicha cláusula?, ¿son aplicables en este supuesto los arts. 111 ó 135 de los Reglamentos de Bienes del Estado y de Navarra? Con el fin de responder a estas cuestiones volveremos a acudir a la jurisprudencia y nuevamente comprobaremos que ha habido oscilaciones.

Sostienen que la cláusula reversional solamente es aplicable cuando la enajenación fue onerosa las siguientes sentencias:

\section{S. 26 de mayo de 1997 (R. 3984) ${ }^{12}$ :}

«CUARTO._... si en las bases de aquél [del pliego de condiciones] se establece que ... las parcelas objeto del contrato revertirán automáticamente de pleno derecho al patrimonio de la Diputación ... resulta evidente cómo la Diputación ... estaba facultada para declarar la resolución del contrato (artículo 65.1 del Reglamento de Contratación de las Corporaciones Locales de 9 de enero de 1953) ante el manifiesto incumplimiento ... de las concretas obligaciones ..., y aunque no estuviera amparada tal facultad en el artículo 97 del Reglamento de Bienes invocado por la Corporación, por contemplar exclusivamente cesión gratuita de bienes patrimoniales».

- S. 11 de diciembre de 1978 (R. 1817/1979):

«CONSIDERANDO: ... cuya inobservancia por el accipiens determina la reversión prevista en el art. 97, ap. 2 del Reglamento de Bienes de las Entidades Locales, sólo aplicable a las cesiones a título gratuito o similares, según recientemente se ha especificado en sentencia de esta Sala, mientras que si la enajenación tuvo lugar a título oneroso, la reversión examinada encuentra causa en el expreso pacto o cláusula inserta en el contrato, en este caso de compraventa, ya que las estipulaciones en él señaladas constituyen la ley de las relaciones entre las partes contratantes - S. de 31 de marzo de 1975 (R. 2385) - y el efecto reversional ocasionado por su incumplimiento directamente deriva del hecho de haber consentido y asumido el adquirente las susodichas condiciones u obligaciones con el expresado carácter de carga real, supuesto que es el contemplado por los presentes autos ...».

12 Se trataba de una venta de una finca para la construcción de viviendas de protección oficial. 
- S. 21 de abril de 1978 (R. 2880):

«CONSIDERANDO: ... e) respecto a la no previsión del cumplimiento de los fines, en los plazos marcados en el art. 97 del Regl. de Bienes, de 27 de mayo de 1955, lleva razón el Ayuntamiento al pensar que dicho requisito se refiere a la cesión gratuita de bienes, pero no a supuestos como el de autos, de enajenación, a título oneroso».

En cambio, se pronuncian a favor de que la cláusula es válida y exigible en toda clase de enajenaciones:

\section{- S. 24 de diciembre de 1985 (R. 6405):}

«NOVENO.- Que en cuanto al problema de si la tan citada reversión sólo procede cuando la enajenación lo ha sido a título gratuito, lo que excluiría la cesión onerosa ..., ha de entenderse que el artículo 97 del Reglamento de Bienes es de aplicabilidad "en toda clase de enajenaciones de bienes por los Ayuntamientos" - Sentencia de la Sala Cuarta del Tribunal Supremo de 28 de marzo de 1978 (R. 1388)-, como ya había declarado la resolución - ya citada - de 16 de noviembre de 1973, es donde, tras un examen del precepto reglamentario citado, se llega a la declaración, - a más del carácter automático de la reversión- de que "... de los anteriores extremos, de carácter gramatical, sistemático y finalista debe llegarse en su completa integración a la convicción de la necesidad de aplicar la norma a todo supuesto de transmisión, sea a título oneroso o gratuito, en que se den los requisitos previstos en ella, y a esta conclusión en definitiva se ha llegado por este Alto Tribunal en las sentencias de la Sala Cuarta de 25 de septiembre de 1970 (R. 3742) y 13 de noviembre de 1972 (R. 4730) al referir a dicho precepto los efectos que en aquél se pactaron para lograr la reversión de bienes municipales cedidos mediante precio al no haberse respetado los plazos pactados por los compradores, pues si bien en ambas sentencias operaba el efecto del pacto no dejan de hacer referencias al modo automático de operarse la reversión según la repetida norma para desvanecer las alegaciones del comprador en contra del efecto automático fundando la de 25 septiembre 1970 en su cuarto considerando el efecto automático de la reversión en estar estipulada y en ser preceptiva reglamentariamente" (...)».

\section{- S. 28 de marzo de 1978 (R. 1388):}

«CONSIDERANDO: ... que todas las cesiones de bienes patrimoniales quedarán sujetas a estas condiciones: ... y cuyas disposiciones [las del art. 97.2 del RBEL] si bien establecen que esta cláusula de reversión es válida y exigible en toda clase de enajenaciones de bienes de los Ayuntamientos, ...».

\section{- S. 16 de noviembre de 1973 (R. 4107):}

«CONSIDERANDO 5. : Que ... el art. 97 del Reglamento de Bienes de las Entidades Locales, aprobado por Decreto de 27 de mayo de 1955, que prevé la reversión de los bienes patrimoniales a dichas entidades cuando sus adquirentes hayan incumplido durante el plazo de cinco años los fines para los que se hubieren cedido, a cuya pretensión opone la Administración del Estado que dicha norma no es aplicable por referirse sólo a los actos a título gratuito, a lo que objeta a su vez la Corporación municipal que no cabe esa distinción por no contenerse en el precepto indicado. 
CONSIDERANDO $6^{\circ}:$ Que aunque efectivamente el art. 97 referido no establece distinción alguna lo que abonaría su aplicación a todas las transmisiones verificadas por una Entidad Local, es preciso corroborar esta interpretación inicial con otros medios interpretativos dada la trascendencia del problema debiendo partirse para ello de los siguientes datos: $1 .^{\circ}$, el art. 97 al hablar de cesiones sugiere la duda de si emplea este término como equivalente a cesión gratuita ya que anteriormente se alude con separación a los actos de enajenación, gravamen y permuta (artículo 95,1 ) y a las cesiones gratuitas (art. 95,2 y 5, art. 96,1), pero esta apreciación se desvanece completamente ante el supuesto contemplado en el art. $96,2 \ldots ; 2 .^{\circ}$, esta ambivalencia del término cesión para los actos a título gratuito y a título oneroso no es extraña a otras leyes y así en la del Suelo de 12 de mayo de 1956, se refiere al término cesión a ambos títulos en su art. 153 y en el 155 a la enajenación por precio, y el Reglamento del Patrimonio del Estado de 5 de noviembre de 1964, se refiere la palabra cesión a la venta en sus arts. 146 y 147, y finalmente en relación con el art. 96 del propio Reglamento de Bienes de las Entidades Locales, la Orden de 21 de septiembre de 1955 , dictadas para su interpretación alude en su art. $4 .^{\circ}$ a la cesión de terrenos mediante precio cuando no fuere practicable el procedimiento normal de permuta a que se refiere dicho precepto; $3 .^{\circ}$, el evidente criterio finalista que inspira el art. 97 que se está interpretando tanto puede darse en las transmisiones gratuitas como en las onerosas, pues la Corporación cedente pudo tener en cuenta el destino de los bienes al enajenarlos mediante precio ya a efectos urbanísticos generales como para lograr la instalación o mejora de algún centro de especial interés para el Municipio; y $4 .^{\circ}$, de los anteriores extremos, de carácter gramatical, sistemático y finalista debe llegarse en su completa integración a la convicción de la necesidad de aplicar la norma a todo supuesto de transmisión, sea a título oneroso o gratuito, en que se dan los requisitos previstos en ella, y a esta conclusión en definitiva se ha llegado por este Alto Tribunal en las Sentencias de la Sala 4. de 25 de septiembre de 1970 y 13 de noviembre de 1972, al referir a dicho precepto los efectos que en aquel caso se pactaron para lograr la reversión de los bienes municipales cedidos mediante precio al no haberse respetado los plazos pactados por los compradores, pues si bien en ambas sentencias operaba el efecto del pacto no dejan de hacer referencias al modo automático de operarse la reversión según la repetida norma para desvanecer las alegaciones del comprador en contra del efecto automático fundando la de 25 de septiembre de 1970 en su $4 .^{\circ}$ considerando el efecto automático de la reversión en estar estipulada y en ser preceptiva reglamentariamente».

\section{S. 25 de septiembre de 1970 (R. 3742):}

«CONSIDERANDO $3 .^{\circ}$ (de la sentencia apelada): ..., cláusula reversional estereotipada en el art. 97-2 del Reglamento de Bienes de las Corporaciones Locales exigible en toda clase de enajenaciones de bienes de los Ayuntamientos de España ...

CONSIDERANDO 4..$^{\circ}$ (de la sentencia apelada): ... en el art. 97-2 del aludido Cuerpo legal [RBEL], en el cual se establece la reversión que nos ocupa para todas las cesiones de bienes patrimoniales ...». 
Después de exponer la doctrina jurisprudencial en este apartado, debemos dar nuestra opinión al respecto:

1. Si la cesión ha sido gratuita, la reversión procede por imperativo legal, conste o no conste en el acuerdo o en el pliego de condiciones que sirvió para la enajenación. Coincidimos con la S. de 11 de diciembre de 1978 (R. 134/1979) en que en los Reglamentos de Bienes - tanto estatal como de Navarra- los conceptos de enajenación y cesión de bienes están debidamente diferenciados y contrapuestos, reservándose la última denominación para las que se hacen a título gratuito.

2. Si estamos ante una enajenación onerosa, con una finalidad determinada por el ayuntamiento vendedor que haya introducido alguna condición resolutoria, procederá la reversión si se incumple dicha condición. Pero no cabe confundir esta reversión con la imperativa limitación de los artículos 111 y 135 de los Reglamentos de Bienes a que venimos haciendo referencia.

3. Si la enajenación fue onerosa pero no se impusieron ni finalidades determinadas ni condiciones resolutorias, no será posible que revierta el bien al patrimonio municipal. Ningún precepto exige - dice también la $S$. de 11 de diciembre de 1978 (R. 134/1979) - que las enajenaciones a título oneroso hayan de hacerse en beneficio de una finalidad concreta de interés público, sino que su finalidad inmediata es la genérica de constituir fuente de ingreso para el erario municipal. Es un axioma jurídico nunca discutido - recogido en la $S$. de 30 de mayo de 1989 (R. 4081) - que los contratos obligan a las partes contratantes en razón a su coincidente voluntad de cumplimiento de sus prestaciones respectivas y a asumir las cargas que se estipularon, los riesgos posibles y las ventajas que puedan obtenerse, sin que ninguna de dichas partes pueda impedir ni participar en las ganancias que la otra legítimamente consiga; de lo cual se deduce que la observancia estricta de las cláusulas aceptadas es lo que constituye la regla general en la vida del contrato y su perfecta ejecución y normalidad.

\section{Causas concurrentes para que el bien pueda revertir}

Es obvio que para que se pueda aplicar la institución de la reversión -con independencia de que estemos ante una cesión o ante una enajenación- ha debido de haber un incumplimiento por parte del adquirente. Pero no debe de concurrir nunca culpabilidad del ayuntamiento que haya imposibilitado al adquirente cumplir el contrato en los términos previamente aceptados; es decir, si no existe incumplimiento contractual imputable al contratista resultará obviamente improcedente la resolución contractual decidida por la Administración y, 
LA REVERSIÓN DE LOS BIENES ENAJENADOS O CEDIDOS ...

como consecuencia, resultará asimismo improcedente la reversión del terreno. Como dice la S. de 28 de diciembre de 1987 (R. 9848):

\begin{abstract}
«CUARTO.- Hay que estar, por el contrario, a lo declarado por otras Sentencias de esta Sala, entre ellas la de 28 de junio de 1980 (R. 3365) ... a tenor de la cual la reversión "como tiene declarado reiteradamente este Tribunal requiere una voluntad deliberadamente rebelde al cumplimiento de lo convenido, $o$ un hecho obstativo que, de un modo absoluto, definitivo e irreformable, impida el cumplimiento", ...».
\end{abstract}

El Tribunal Supremo ha dicho en varias ocasiones que el instituto de la reversión no puede ser automático, no tiene un carácter monolítico, sino que son admisibles matizaciones que tiendan a acercarlo a la realidad del humano obrar, aun manteniendo su finalidad de defensa específica del patrimonio de las Entidades y Corporaciones (SS. de 10 de diciembre de 1988, R. 9772, 23 de junio de 1987, R. 6521, 29 de diciembre de 1986, R. 1676/1987, 7 de octubre de 1986, R. 7427, 28 de marzo de 1978, R. 1388). No hay que olvidar que en toda relación jurídica - administrativa o no- hay que averiguar cuál sea la causa determinante de que sus prestaciones no se cumplan, a fin de aplicar a aquélla la solución que al caso convenga, por la elemental y lógica circunstancia de que nadie está obligado a hacer lo que le es imposible, ya se tenga certeza de esta imposibilidad al tiempo de contratar, ya sobrevenga durante la vida del contrato pero siempre antes de que la obligación, condicionada o no, se cumpla (S. 28 de diciembre de 1987, R. 9848).

De cuanta jurisprudencia hemos leído para el presente trabajo, podemos entresacar varios motivos que se han aceptado por el Alto Tribunal como causas suficientes para justificar los acuerdos de las Administraciones sobre la rescisión del contrato y la reversión de los inmuebles:

- Incumplimiento del plazo de construcción (de viviendas, de fábricas): 26 de mayo de 1997 (R. 3984), 18 de junio de 1996 (R. 5232), 27 de enero de 1988 (R. 484), 4 de noviembre de 1986 (R. 7747), 23 de octubre de 1985 (R. 6292), 27 de septiembre de 1983 (R. 5771), 21 de junio de 1976 (R. 4172), 16 de noviembre de 1973 (R. 4107), 2 de marzo de 1973 (R. 971), 21 de noviembre de 1972 (R. 5049), 16 de noviembre de 1972 (R. 4748), 13 de noviembre de 1972 (R. 4730) y 25 de septiembre de 1970 (R. 3742).

- Incumplimiento del destino o fines específicos: 25 de noviembre de 1996 (R. 8229), 27 de febrero de 1993 (R. 1303), 18 de junio de 1990 (R. 4766), 24 de diciembre de 1985 (R. 6405), 11 de diciembre de 1978 (R. 1817/1979) y 16 de noviembre de 1962 (R. 382/1963). 
- Las dificultades económicas del contratista no son causa de fuerza mayor ${ }^{13}$ : 18 de junio de 1996 (R. 5232), 27 de enero de 1988 (R. 484) y 11 de diciembre de 1978 (R. 134/1979).

- Extinción de una persona jurídica (Organización Sindical, Falange Española Tradicionalista y de las Jons): 27 de febrero de 1993 (R. 1303), 31 de octubre de 1988 (R. 8338) y 3 de febrero de 1986 (R. 894).

- Impago del precio: 19 de mayo de 1992 (R. 4460).

Por el contrario, el Tribunal Supremo ha denegado la reversión en los siguientes casos:

- Prescripción de acciones por transcurso del plazo contratado y, en todo caso, por el de 30 años: 24 de enero de 1996 (R. 34), 23 de noviembre de 1992 (R. 9210), 11 de diciembre 1978 (134/1979). Las de 26 de enero de 1987 (R. 1987) y 19 de noviembre de 1986 (R. 8087) entienden que se consentía una ampliación del plazo por haberse concedido licencia de construcción sin haber resuelto el contrato por incumplimiento del plazo; lo que se debía hacer, antes de otorgarse, era declarar resuelto el contrato. Sin embargo, en sentido contrario está la de 4 de noviembre de 1986 (R. 7747), según la cual el hecho de que el Ayuntamiento hubiese concedido licencia de obras por acuerdo de la Comisión Municipal Permanente, no impide que pueda revertir la parcela por cuanto esta decisión no puede vincular al órgano plenario competente para resolver el contrato y acordar la reversión.

- Imposibilidad de construir por inidoneidad de la calificación urbanística de los terrenos: 15 de mayo de 1990 (R. 4075), 10 de diciembre de 1988 (R. 9772), 29 de diciembre de 1986 (R. 1676/1987) y 4 de febrero de 1985 (R. 987).

- Mantenimiento de los fines: 23 de noviembre de 1992 (R. 9210), 30 de mayo de 1989 (R. 4081), 28 de marzo de 1978 (R. 1388), 28 de diciembre de 1987 (R. 9848) y 8 de mayo de 1962 (R. 2209).

- Imposibilidad de inscribir la escritura en el Registro de la Propiedad: 5 de enero de 1988 (R. 185) y 4 de febrero de 1985 (R. 987).

13 Ésta consiste, según las SS de 23 de octubre de 1969, R. 4829, 9 de junio de 1976, R. 3553, y 24 de diciembre de 1985, R. 6405, en un «suceso que está fuera del cúrculo de actuación obligado que no hubiera podido preverse o que, previsto, fuera inevitable", lo que supone la total extraneidad del acontencimiento en relación con la parte obligada, como también requieren las de 12 de marzo de 1956 ( $R$. 1511), 19 de mayo de 1960 (R. 1741) y 11 de diciembre de 1978 (R. 134/1979). 
LA REVERSION DE LOS BIENES ENAJENADOS O CEDIDOS ..

- Falta de entrega de las parcelas adjudicadas: 11 de noviembre de 1985 (R. 359/1986).

- Los terrenos no tienen que soportar necesariamente las construcciones: 28 de marzo de 1978 (R. 1388).

- La explotación efectiva de la industria puede realizarse por persona distinta de la cesionaria: 28 de marzo de 1978 (R. 1388).

- Dificultades económicas generadas por el propio Ayuntamiento, que giró indebidamente una liquidación de plus-valía: 29 de diciembre de 1986 (R. 1676/1987).

\section{Procedimiento administrativo a seguir}

Tampoco ha sido ésta una cuestión pacífica: nos encontramos con sentencias, eso sí, las menos y las más antiguas, que dicen que no hay que seguir ningún procedimiento para que el bien revierta al patrimonio municipal y otras, en cambio, que exigen, al menos, audiencia del interesado.

Entre las primeras, están:

- SS 21 y 16 de noviembre de 1972 (RR. 5049 y 4748):

«CONSIDERANDO $6 .^{\circ}$ (de la sentencia apelada): Que ... la reversión opera automáticamente y de pleno derecho al patrimonio municipal y, no requiere la formación de expediente para ello, que es en definitiva lo que consagra el art. 65 , núm. 1. del Reglamento de Contratación de las Corporaciones Locales».

- S. 13 de noviembre de 1972 (R. 4730):

«CONSIDERANDO 4. ${ }^{\circ}$ (de la sentencia apelada): Que ... la medida reversional ... opera automáticamente y de pleno derecho no tanto por venir así configurado al establecerse conminativamente, como por la propia expresión literal de la norma citada, es decir, como ha dicho el TS ipso facto per se en cuanto los plazos quedan incumplidos, ya que tal es el significado del automatismo y de la sobrevivencia de pleno derecho que excluyen la necesidad de otra intervención para que se dé el resultado reversional; y con ello quedan rechazadas dos alegaciones que el recurrente ha hecho como enervantes de la reversión: la que denuncia la falta de un expediente especialmente dirigido a la reversión a su juicio necesario y aquella otra que reclama como requisito y exigencia, innecesariamente procedente, la práctica de requerimiento en forma, ...». 
- S. 25 de septiembre de 1970 (R. 3742):

«CONSIDERANDO (del TS): Que tampoco reviste consistencia la tesis de mayor amplitud en la apelación, de que una vez adjudicado ... el solar ... no podía revertir a la Corporación y menos darle por revertido sin la formalización previa de expediente justificativo del recobro, pues, por el contrario, ..., la condición 4. ${ }^{\mathrm{a}}$ del pliego ... añade que de no comenzar la edificación o no terminarla en esos tiempos se entenderá por no entrados en posesión del solar y revertirá el mismo al Ayuntamiento automáticamente y claro que aceptada plenamente por los adjudicatarios tal cláusula enunciativa del evento resolutorio e implícitamente conminatorio, a ella quedaron vinculadas por entero en el alcance y en el modus operandi de la misma como ley rectora del caso, pero con idéntico sentido el art. 97 del Reglamento de Bienes ...».

Entre las segundas, las que sí exigen la existencia de un procedimiento, encontramos varias, todas ellas más recientes que las anteriores:

- S. 23 de noviembre de 1992 (R. 9210):

«TERCERO (de la sentencia apelada). - ... llama la atención de esta Sala en primer término que se inicia un expediente ... y que en dicho expediente no se oiga durante su tramitación y antes de dictar resolución al titular registral del inmueble cuya reversión se acuerda...».

- S. 19 de mayo de 1992 (R. 4460):

"TERCERO.- (...) 3. ... es infracción del ordenamiento jurídico que se resuelva el contrato sin dar audiencia al interesado; ...».

- S. 26 de enero de 1987 (R. 1987), que anula la resolución del contrato por considerar incongruente esa decisión con el pliego de cargos formulado por la Administración.

- S. 28 de marzo de 1978 (R. 1388):

«CONSIDERANDO (del TS): ... no es posible admitir el automatismo de la citada reversión aun cuando así se haya estipulado, ya que en todo caso la misma no puede producir su efecto ipso facto sin un previo señalamiento de plazo o término para que la misma se produzca, aun en el supuesto, ..., de que se haya dejado de cumplir en su totalidad la finalidad que motivó la cesión de que se trata».

- S. 21 de junio de 1976 (R. 4172):

«CONSIDERANDO (del TS): Que al no haberse producido, ..., un propio requerimiento municipal ni pronunciamiento alguno en orden a la resolución del contrato de compraventa o a la devolución de las parcelas vendidas sino simplemente una decisión de iniciar un expediente que se denomina de reversión de las parcelas no edificadas y que obviamente se habrá de encaminar a la adopción de los acuerdos pertinentes a tal fin, resulta patente que este otro aspecto del contenido de la resolución impugnada es simplemente un acto de trámite en cuanto su única decisión se encamina tan sólo a 
LA REVERSION DE LOS BIENES ENAJENADOS O CEDIDOS ..

la ulterior incoación de un prócedimiento en el cual dichas decisiones puedan adoptarse, ...».

Nuestra opinión no puede ser sino favorable a que se debe de dar audiencia al interesado antes de acordar la resolución o rescisión del contrato y la reversión del bien. Así creemos que se deriva del carácter claramente sancionador del propio expediente: nadie puede ser condenado sin ser antes oído. Y ya hemos visto anteriormente que pueden darse casos en que el interesado impute a la Administración la culpa de no haber podido cumplir con los fines específicos impuestos en la enajenación o cesión del bien o, incluso, que el plazo para realizar la reversión todavía no hubiera transcurrido. A nuestro juicio, se incurriría en indefensión y, por consiguiente, el acuerdo que se adoptase sería nulo de pleno derecho, a tenor del artículo 62.1.a) y e) de la Ley 30/1992, de 26 de noviembre, de Régimen Jurídico de las Administraciones Públicas y del Procedimiento Administrativo Común.

También la legislación que regula los contratos de las Administraciones Públicas ${ }^{14}$ establece la obligación previa de dar audiencia y de que se emita, al menos, informe jurídico.

No hemos de olvidar tampoco que es a la Administración a quien le corresponde demostrar que ha habido incumplimiento, sin que se pueda argumentar, tras la adopción del acuerdo, que éste goza de presunción de veracidad y legalidad, por cuanto supondría trasladar la carga de la prueba al interesado. En este sentido nos encontramos con la Sentencia de 8 de mayo de 1962 (R. 2209):

«CONSIDERANDO: Que al no haberse probado por la Corporación Municipal actora que los terrenos objeto de la reversión hayan quedado desafectados del servicio público, a que se destinan a virtud de resolución definitiva de la Autoridad aérea competente, queda sin base jurídica la pretensión por aquélla deducida, ...».

Más recientemente, S. 23 de noviembre de 1992 (R. 9210), el Tribunal Supremo también desestima una pretensión de reversión de un ayuntamiento porque:

«a juicio de esta Sala, de una valoración del conjunto de la prueba practicada en primera instancia tampoco resulta probado que los ganaderos y agricultores hayan dejado de usar el almacén-granero para el fin para el que fue construido, como también ha apreciado la Sala sentenciadora».

14 Ley 13/1995, de 18 de mayo, de Contratos de las Administraciones Públicas y, más concretamente, el Real Decreto 390/1996, de 1 de marzo, que la desarrolla, y, en Navarra, la Ley Foral 13/1986, de 14 de noviembre, de Contratos de la Administración de la Comunidad Foral de Navarra, aplicable a las entidades locales de Navarra por expresa disposición del artículo 22.4.2 de la Ley Foral 6/1990, de 2 de julio, de la Administración Local de Navarra. 
No podemos olvidar que las entidades locales deben velar por la conservación, defensa, recuperación y mejora de los bienes y derechos de su patrimonio, y tienen la obligación de ejercer las acciones necesarias para la defensa de los mismos - art. 68.1 de la LRBRL, art. 9.2 del RBEL y art. 220.1 del ROFRJEL y, en Navarra, el art. 110.1 de la LFALN y art. 25.1 del RBELN-, incluyéndose la potestad de investigación, la cual puede iniciarse por una denuncia de un particular, además de incoarse de oficio. Y en esta defensa del patrimonio tiene gran importancia el inventario de los bienes, cuya confección y mantenimiento es obligatorio, puesto que «para la correcta conservación de los bienes es saber de su existencia y de su vinculación a la Entidad Local» ${ }^{15}$; y precisamente el epígrafe $80^{\circ}$ de los inventarios tiene que reseñar los bienes y derechos revertibles, a modo de recordatorio.

\section{Consecuencias del acuerdo de resolución o rescisión del contrato}

Nos veremos obligados a distinguir entre cesión gratuita o enajenación onerosa a la que se ha impuesto una finalidad determinada.

Evidentemente, en ambos casos, el incumplimiento de las condiciones impuestas provoca la resolución o rescisión del contrato y, como primera consecuencia y la más importante, la reversión del bien al patrimonio municipal.

Ahora bien, surgen inmediatamente unas dudas que hemos de resolver: ¿revierten también las construcciones que se hayan realizado sobre los terrenos?; ¿debe la Administración pagar para que se produzca la reversión?; ¿se produce un enriquecimiento injusto en favor de la Administración? Cuestiones, sin duda, de gran importancia y que todas ellas deberían tener su correspondiente respuesta, clara y sin que hubiese lugar a dudas ni interpretaciones, en el pliego de condiciones que sirvió para la enajenación o en las condiciones impuestas en el acuerdo de cesión; es, pues, aquí donde primero habrá que ir para adoptar la decisión que se ajuste a Derecho, puesto que, utilizando palabras del Tribunal Supremo (S. 30 de mayo de 1989, R. 4081):

«... "el contrato es ley entre las partes, lo mismo en la esfera civil que en la administrativa, cuando los términos de sus cláusulas son claros y terminantes sin que susciten dudas ni titubeos en su interpretación, por eso, las incidencias derivadas de la interpretación y cumplimiento de los contratos han de resolverse de absoluta conformidad a lo convenido y libremente concertado por las partes, en vista del principio general anteriormente expuesto"; ...».

15 Demetrio LoPERENA Rota, obra citada, pág. 23. 
LA REVERSIÓN DE LOS BIENES ENAJENADOS O CEDIDOS ..

Siempre, como dice la S. de 3 de febrero de 1986 (R. 894), con cita de la de 11 de diciembre de 1978 (R. 134/1979), habrá que examinar cada caso en concreto, puesto que afecta a la equidad.

\subsection{Cesiones gratuitas}

Procede ya sacar a colación la S. de 23 de junio de 1987 (R. 6521), para la cual:

«SEGUNDO.- Que ... ante precepto tan claro y contundente ${ }^{16}$, sin necesidad de interpretación, debe darse lugar a la reversión con todas las consecuencias previstas, por lo que ni resulta aplicable la normativa de Derecho privado referente a la cesión, ni puede invocarse la teoría del enriquecimiento injusto, ya que éste carece de existencia cuando la atribución patrimonial responde a relaciones jurídicas derivadas de un contrato o de la imposición de un precepto legal específico y determinado, como ocurre en el caso de estos autos».

Es decir, que la reversión procedería aunque no figurase en el acuerdo municipal de cesión, puesto que aquélla nace ope legis —en este sentido se ha pronunciado la jurisprudencia ya citada de 27 de febrero de 1993 (R. 1303) y 18 de junio de 1990 (R. 4766), ambas de la Sala de lo Civil-, y además se produciría «con sus pertenencias y accesiones» (arts. 111.3 y 135.2 de los Reglamentos de Bienes del Estado y de Navarra, respectivamente).

Por la reversión, el Ayuntamiento no debe pagar nada al cesionario, salvo que se haya pactado lo contrario. Procede reproducir la S. de 18 de junio de 1990 (R. 4766), Sala de lo Civil, pues, aunque extensa, es sumamente ilustrativa:

«TERCERO.- Las características en que fue concertada la donación gratuita referida y concretamente la singular circunstancia de que se hubiese expresamente convenido que para el supuesto de que no se hubiesen cumplido las obligaciones estipuladas, ..., el bien cedido revertiría automáticamente de pleno derecho al Patrimonio municipal del Ayuntamiento de Galdakao "con todas sus pertenencias y accesiones", sin estipulación alguna a que esa reversión fuese sobre la base de indemnización alguna, conduce a la estimación de los relacionados motivos tercero, cuarto y quinto, que por diferentes vías razonadoras tienden a la eficacia de la reversión solicitada, sin previo pago de cantidad alguna, puesto que esa determinación de reversión con derecho al referido Ayuntamiento a las accesiones, sin supeditación a abono alguno de su importe, claramente está poniendo de manifiesto que el reintegro, en todo caso, de la parcela cedida gratuitamente habrá de ser en las mismas condiciones de gratuidad con que había sido cedida, pues de no ser así lógicamente se habría consignado su condicionante al reintegro del importe de lo que fuese objeto de accesion, y ya

16 Aunque se refiere al artículo 97.2 del antiguo Reglamento de Bienes, sirve para los actuales, tanto del Estado como de Navarra. 
que el entender lo contrario tanto significaría establecer un gravamen económico a cargo del cedente que podía hacer ilusorio su derecho de reversion, en cuanto el valor de lo accedido alcanzase valor desproporcionado con relación al bien gratuitamente cedido; todo lo cual lleva a considerar que la sentencia recurrida incide en infracción de los preceptos legales invocados por el Ayuntamiento de Galdakao recurrente como base fundamentadora de los precitados motivos tercero, cuarto y quinto, pues, de una parte, si como viene indicado la reversión del terreno de que viene haciendo mencion ha de ser con sus accesiones, sin indemnización alguna, claro es que ninguna aplicación tienen al supuesto contemplado lo normado en los artículos 361,453 y 454 del Código Civil, y más si se tiene en cuenta que lo considerado en dicho artículo 361 , referente a la accesión por edificación en terreno ajeno, no es de ortodoxa aplicación en el presente caso, en que la edificación de la Casa Sindical sobre el terreno cedido gratuitamente por el mencionado Ayuntamiento de Galdakao ha tenido lugar en consideracion a hacerse sobre suelo propio, a causa de dicha cesión, ya que la Organización Sindical, una vez formalizada la escritura correspondiente pasó a ser propietaria del meritado terreno, aunque con las condiciones estipuladas de construir dentro de los cinco años siguientes - lo que fue efectuadoy mantenerse el destino de dicha Casa Sindical construida durante los treinta años siguientes - lo que no sucedió - determinando el pacto resolutorio para el caso de incumplimiento de cualquiera de dichas condiciones posibilitador de la reversión solicitada mediante la demanda iniciadora del juicio de que se trata, con las accesiones que se hubieran producido en el terreno, sin supeditación a indemnización alguna; de otra parte debido a que el principio pacta sunt servanda, emanante del contenido en los artículos 1089, 1091 y 1278 del Código Civil, hace que sea operante la expresada reversión solicitada, sin precisión de previa indemnización de sus accesorios cual es la edificación construida en el terreno en cuestión para Casa Sindical, sin supeditación por ello a indemnización alguna, dado que precisamente ese destino a Casa Sindical, durante el período de tiempo convenido de los treinta años siguientes a tal construcción, fue el motivo esencial, y en consecuencia causa condicionante, de la cesión gratuita llevada a cabo, con el consiguiente efecto viabilizador que a tal condición deparan los artículos 1114 y 1115 del Código Civil; ... establecía en su apartado 1 las condiciones a que se sujetaban las cesiones gratuitas de bienes patrimoniales, consistentes en el cumplimiento de los fines determinantes de la cesión en el plazo máximo de cinco años y el mantenimiento de su destino durante los treinta siguientes, y en el apartado 2 del referido precepto administrativo, al prevenir las consecuencias que acarreaba el incumplimiento de dichas condiciones, se disponía que "transcurridos uno u otro plazo - es decir, cinco y treinta años aludidossin que se hubieran cumplido las citadas condiciones, los bienes revertirán automáticamente de pleno derecho al patrimonio de la Entidad cedente con sus pertenencias y accesiones", lo que tanto significa, por dichas expresiones "automáticamente de pleno derecho", "con sus pertenencias y accesiones", que la reversión había de ser, de producirse la causa de incumplimiento de condición que la motivaba, sin supeditación a condicionante alguno, y por tanto impedía indemnización por ningún concepto».

En el mismo sentido están las Sentencias de 27 de febrero de 1993 (R. 1303), 31 de octubre de 1988 (R. 8338), 15 de febrero de 1985 (R. 2647), que condiciona la gratuidad de la reversión a que el Ayuntamiento cedente no haya 
LA REVERSION DE LOS BIENES ENAJENADOS O CEDIDOS ...

provocado, intervenido o coadyuvado de alguna forma al incumplimiento, 11 de diciembre de 1978 (R. 134/1979) y 16 de noviembre de 1962 (R. 382/1963).

Sin embargo, la S. de 3 de febrero de 1986 (R. 894) nos hace dudar de la conclusión anterior:

«PRIMERO. - ... ha quedado acreditado que la cesión gratuita efectuada para unos fines determinados quedo inatendida y como la satisfacción de tales fines es lo que justifico causalmente la cesión cuando dichos fines quedan incumplidos la rescisión se produce automáticamente conforme a los términos inequívocos del artículo 97.2 del Reglamento de Bienes de las Corporaciones Locales de 27 de mayo de 1955, sin perjuicio de las acciones que pudiera ejercitar la Administración conforme a lo establecido en el artículo 453 del Código Civil u otras disposiciones aplicables, porque este derecho no queda desvirtuado por los términos del artículo 97.2 citado por ser norma de rango inferior y se limita a señalar los efectos de la reversión sin que implique derogación de principios tales como el que veda el enriquecimiento injusto y los que regulan los efectos de la posesión de buena fe,...».

De lo que no hay duda es de que si en la reversión hay culpabilidad del Ayuntamiento, éste deberá hacerse cargo de los gastos que el cesionario haya realizado: en este sentido se pronunció la S. de 29 de diciembre de 1986 (R. 1676/1987).

Además, se producirá pérdida de la fianza definitiva, si es que se exigió para responder del buen fin de la cesión gratuita.

\subsection{Enajenaciones onerosas}

Creemos que la S. de 25 de noviembre de 1996 (R. 8229) nos aporta luz respecto de los interrogantes que hemos planteado:

«SEGUNDO.- ... y por último, sus alegatos en contra del Ayuntamiento por, en opinión del mismo, llevar la resolución a un enriquecimiento injusto para aquél, son totalmente improcedentes, por cuanto fue convenio entre las partes, apartados tercero y octavo de la escritura pública, que al término del arrendamiento el terreno revertiría al Ayuntamiento con cuantas obras e instalaciones se hubiesen realizado en el mismo, sin derecho a indemnización por parte del arrendatario, y que en caso de resolución el arrendatario no tendría derecho a reclamación alguna, lo que dota de causa al posible enriquecimiento municipal y lo desposee de injusticia alguna».

Es decir, que si está pactada la reversión del terreno y de las construcciones y que esta reversión sea de forma gratuita, no hay duda alguna de cómo se tiene que actuar. 
Ahora bien, ¿qué ocurrirá si está pactada la reversión, pero se ha omitido si ésta será o no gratuita? Parece ser que deberíamos acudir al Código Civil para resolver esta cuestión y el artículo 1295 dice:

«La rescisión obliga a la devolución de las cosas que fueron objeto del contrato con sus frutos, y del precio con sus intereses; en consecuencia, sólo podrá llevarse a efecto cuando el que la haya pretendido pueda devolver aquello a que por su parte estuviese obligado».

Esto parece desprenderse de las SS. de 21 y 16 de noviembre de 1972 (RR 5049 y 4748):

«CONSIDERANDO $5 .^{\circ}$ (de las sentencias apeladas): Que, en cuanto al referido art. $6^{\circ}$ del pliego de condiciones, establece para los adquirentes la obligación de edificar en cierto plazo con la consecuencia, para el caso de incumplimiento, de pérdida de la propiedad, según se dice, que revertirá al Ayuntamiento, ..., nos encontramos en este caso con una condición que es resolutoria, por cuanto en contraposición a las suspensivas, puede dar lugar a la ineficacia del contrato por resolución del mismo; potestativa por cuanto a diferencia de las casuales y mixtas, el cumplimiento del evento depende de la voluntad de la parte obligada; y que una vez cumplido - momento de la conditio existit o condición cumplida-, producirá los efectos estipulados y en su defecto, los señalados en las disposiciones legales ya citadas, esto es, devolución recíproca de la cosa y precio,...».

Es evidente, que si en el incumplimiento de las condiciones resolutorias ha habido culpabilidad del Ayuntamiento, sí que procede que éste devuelva el precio que recibió, incrementado con los intereses legales, además de indemnizar al adquirente por los gastos, a la postre innecesarios, a los que haya tenido que hacer frente. En este sentido se pronuncia la S. de 15 de mayo de 1990 (R. 4075):

«DECIMOTERCERO.- Ante este desigual reparto de papeles, dentro de la conducta observada por las partes implicadas en este supuesto, malamente deberá ser premiada la que la peor la ha observado -el Ayuntamiento-, ya que, de lo contrario, se provocaría un enriquecimiento suyo, sumamente injusto. A costa precisamente de la parte de adverso, de conducta más justificada.

Por ello, nada más natural y lógico que el actor, al verse privado de la parcela por él adquirida, recupere el precio pagado por la misma: 2.500.000; así como los gastos satisfechos por él, en relación con esta operación: licencia municipal, anotación preventiva en el Registro, notaría, fianza, anuncios oficiales de la subasta. Así como el importe de los honorarios de lōs facultativos autores de los dos Proyectos presentados y de un Ante-proyecto, ya que si no se llegó a visar uno de aquéllos fue, como antes dijimos, por los impedimentos urbanísticos no imputables al recurrente. (...)

... Por último, en cuanto al pago de intereses legales, se impone también el pronunciamiento de la sentencia que nos ocupa, que dejó su determinación al período de ejecución de la misma». 
LA REVERSIÓN DE LOS BIENES ENAJENADOS O CEDIDOS ..

También, como en las cesiones, se producirá la pérdida de la fianza que se hubiese depositado para garantizar el cumplimiento de los fines estipulados en la enajenación.

\section{CONCLUSIONES}

De cuanto hemos expuesto, con más o menos acierto, hemos pretendido resaltar que el Ayuntamiento, bien en el correspondiente pliego de condiciones, bien en el acuerdo de cesión gratuita, debe preocuparse de expresar claramente las obligaciones que el adquirente - oneroso o gratuito - tiene que cumplir, el plazo para hacerlo y todas las consecuencias que se vayan a derivar del incumplimiento. En su mano está pues no tener que acudir a interpretaciones cuando concurran circunstancias que hagan entrar en juego a la institución de la reversión.

La institución que nos ocupa es solamente una consecuencia de la resolución o rescisión del contrato; por tanto, primero se tendrá que producir un acuerdo municipal de resolución o rescisión del contrato de compraventa o de cesión gratuita por incumplimiento de los fines para los que se enajenó el bien o por el transcurso de los plazos establecidos para destinarlo a esos fines específicos. En caso de incumplimiento, que debe ser demostrado por la Administración, se incoará expediente, en el que se dará audiencia al interesado, que concluirá con el acuerdo de resolución o rescisión y con el de reversión.

Si la enajenación fue onerosa y no se impusieron finalidades determinadas ni condiciones resolutorias, no será posible que el bien revierta al patrimonio municipal.

Para que proceda la reversión, no debe de concurrir nunca culpabilidad de la Administración Local que haya imposibilitado al adquirente cumplir el contrato. También esta culpabilidad tendrá incidencia en si procede indemnización o no tras la resolución o rescisión del contrato.

Finalmente, recordar que la reversión de bienes se debe exigir por los ayuntamientos, quienes, no en vano, tienen la obligación de conservar, defender y recuperar su patrimonio. 
